\title{
Toxic effect of single walled carbon nanotubes combined with cadmium to the crustacean Daphnia magna
}

\author{
Messika Revel ${ }^{1,2, a^{*}}$, Michel Fournier ${ }^{2, b}$ Christian Gagnon ${ }^{3, c}$ \\ and Pierre Yves Robidoux ${ }^{2, d}$
${ }^{1}$ INRS-Institut Armand-Frappier, Université du Québec, 538 boulevard des Prairies, Laval, Québec H7V 1B7, Canada \\ ${ }^{2}$ National Research Council of Canada, 6100 Royalmount Avenue, Montréal, Québec H4P 2R2, \\ Canada \\ ${ }^{3}$ Environment Canada, 105 rue McGill, Montréal, Québec H2Y 2E7, Canada \\ amessika.revel@iaf.inrs.ca, ${ }^{\mathrm{b}}$ michel.fournier@iaf.inrs.ca, ${ }^{\mathrm{c}}$ christian.gagnon@ec.gc.ca, \\ pierre.yves.robidoux@hotmail.com
}

Keywords: SWCNT, synergistic toxicity, cadmium, survival

\begin{abstract}
The aim of this study was to assess the impact of single-walled carbon nanotubes (SWCNT) on the toxicity of cadmium (Cd) using the crustacean Daphnia magna. LC50 of Cd and SWCNT alone and combined were calculated and compared. Sorption of Cd on SWCNT was also quantified in separate batch experiments. Results showed that the maximum adsorption of Cd onto SWCNT calculated by the Langmuir equation was $24.4 \mathrm{mg} \mathrm{kg}-1$. LC50s for Cd and SWCNT alone were $252.3 \mu \mathrm{g} \mathrm{L}^{-1}$ and $1400 \mu \mathrm{g} \mathrm{L}^{-1}$, respectively. In the presence of 500 and $1000 \mu \mathrm{g} \mathrm{L}^{-1}$ of SWCNT, Cd LC50s were 127.2 and $120.1 \mu \mathrm{g} \mathrm{L}^{-1}$ respectively. Therefore, Cd toxicity increased when organisms were exposed to both contaminants which indicated that SWCNT induces a synergistic toxic effect on the survival of D. magna. It appears that even if SWCNT had a low adsorption capacity for $\mathrm{Cd}$, toxicity of the metal can be increased. Our study shows the complexity of SWCNT toxicity and how the understanding of their interactions with other contaminants is crucial to determine the consequences of their release into the environment.
\end{abstract}

\section{Introduction}

Carbon based nanomaterials are used in a number of products such as sports equipment, textiles or automobiles (Wijnhoven et al. 2011). Among these nanomaterials, single-walled carbon nanotubes (SWCNT) offer many benefits such as toughness, strength and high conductivity making them of interest for many applications in material science (Dresselhaus et al. 2004). Carbon nanotubes are also widely applied for environmental monitoring and wastewater treatment due to their large surface area (Tan et al. 2012). If the large surface area of SWCNT enhance their ability to adsorb hydrocarbons or metals present in water or soil and hence be of use for decontamination purpose (Baun et al. 2008, Qu et al. 2014), it can also modify the mobility/availability of these contaminants to organisms. The interactions of SWCNT with other contaminants needs to be closely addressed in order to fully understand the environmental impact of these nanomaterials upon release in the environment (Moore 2006).

The toxicity carbon nanotubes has been previously studied on algae (Youn et al. 2012), copepods (Templeton et al. 2006), fish (Cheng et al. 2007, Martinez et al. 2013) and the crustacean Daphnia magna (Petersen et al. 2009, Alloy and Roberts 2011, Li and Huang 2011). The effects measured have been mainly attributed to the action of the carbon nanotube itself, either by blocking the digestive tract and by "sticking" to the body's surface of organisms (Kennedy et al. 2008, Mwangi et al. 2012), or by releasing impurities - most commonly iron, cobalt and nickel embedded in the nanoparticles. A large number of studies reported the ability of carbon nanotubes to adsorb heavy metal ions but few investigated the effect of this property on the organisms potentially exposed ( $\mathrm{Li}$ et al. 2004, $\mathrm{Li}$ et al. 2005, $\mathrm{Lu}$ et al. 2006). A previous study described a potentiating toxicological effect of SWCNT, suspended with organic matter in seawater, co- 
exposed with divalent metals at very low concentration $(\mu \mathrm{g} / \mathrm{L}$ range) on DNA integrity of the mussel Mytilus edulis (Al-Shaeri et al. 2013). In other studies, lead toxicity to a freshwater fish increased in the presence of purified MWCNT (Martinez et al. 2013) while, in contrast, SWCNT in sediments significantly reduced bioaccumulation of hydrophobic carbon to the deposit/suspensionfeeding of a polychaete (Ferguson et al. 2008). Despite these data, very little is known regarding the impact of carbon nanotube on the toxicity of metals to aquatic organisms.

Cadmium $(\mathrm{Cd})$ is a heavy metal very toxic to health and environment at both acute and chronic exposure (Attar and Maly 1982, Bodar et al. 1988, Giusto et al. 2012, Souid et al. 2013). It is one of the most common pollutants found in both industrial and urban effluents due to its presence in batteries, pigments paint, pulp and paper production and wastewater treatment plants (Hare 1992, USGS 2013). Cd is relatively soluble in water and therefore is potentially bioavailable and tends to bioaccumulate in aquatic organisms (Wang and Rainbow 2006, Vellinger et al. 2012). Many studies have shown negative effects, such as decrease in survival (Qu et al. 2013) or growth (Giusto et al. 2012), and oxidative stress on several organisms including D. magna (Wen-Hong et al. 2009, Souid et al. 2013). The use of D. magna as a standard test organism is recommended by many international organizations to test the toxicity of chemicals, effluents, and contaminated water (OECD, Biesinger et al. 2002, Lazorchak et al. 2009).

It is well known that in natural waters, organisms are exposed to a variety of contaminants. In this study, our goal is to identify the potential impact of SWCNT on the toxicity of Cd to the crustacean D. magna. For this purpose, we chose to conduct 48 -h lethality tests with $\mathrm{Cd}$ and SWCNT alone or in combination. A study of the adsorption capacity of SWCNT for Cd was also conducted to evaluate physical interactions between the two toxicants.

\section{Materials and Methods}

\section{Preparation and characterization of SWCNT}

SWCNT provided by Dr. Benoit Simard's research team (NRC Canada) were synthesized using a plasma system modified from a previous method (Kim et al. 2007). The chemical properties of dry SWCNT were measured using thermo-gravimetric analysis (TGA) and Raman spectrometry (WiTec confocal microscope fiber coupled to an Acton 2500i spectrograph fitted with a Roper Scientific CCD array detector). The diameter of SWCNT (D) was calculated from the characteristic radial breathing $(\mathrm{RBM})$ wave number $(\omega)$ using the following relation: $\mathrm{D}(\mathrm{nm})=248 / \omega$. Dynamic light scattering technique (Zetasizer Nano ZS, Malvern Instruments) was used to determine the particle size and electrophoretic mobility of SWCNT suspensions. The latter was calculated from the zeta potential values using the Henry equation (Eq. (1)) with the Smolchenski approximation:

$$
U_{E}=\frac{2 \varepsilon z \mathrm{f}(\mathrm{ka})}{3 \eta}
$$

Where UE is the electrophoretic mobility $\left(\mathrm{m}^{2} \mathrm{~s}^{-1} \mathrm{~V}^{-1}\right), \varepsilon$ is the dielectric constant of the medium, $\mathrm{z}$ is the zeta potential $(\mathrm{mV}), \mathrm{f}(\mathrm{ka})$ is Henry's function and correspond to the ratio of particle radius to double layer thickness (1.5) and $\eta$ is the viscosity $\left(\mathrm{kg} \mathrm{m}^{-1} \mathrm{~s}^{-1}\right)$.

Morphology was determined by field emission gun scanning electron microscopy (FEGSEM, Hitachi 4700) operated at $2 \mathrm{kV}$ and transmission electron microscopy (TEM, Hitachi H7100).

Artificial freshwater called ASTM medium, consisting of $\mathrm{NaHCO}_{3}\left(192 \mathrm{mg} \mathrm{L} \mathrm{L}^{-1}\right), \mathrm{CaCl}_{2}$ $2 \mathrm{H}_{2} \mathrm{O}\left(120 \mathrm{mg} \mathrm{L}^{-1}\right), \mathrm{MgSO}_{4} 7 \mathrm{H}_{2} \mathrm{O}\left(120 \mathrm{mg} \mathrm{L}^{-1}\right)$ and $\mathrm{KCl}\left(8 \mathrm{mg} \mathrm{L}^{-1}\right)$ was prepared with Milli-Q water ( $>18 \mathrm{mV}$ ) according to ASTM E729-96 (ASTM 2014) and does not contain any Cd. SWCNT stock solution $\left(0.1 \mathrm{~g} \mathrm{~L}^{-1}\right)$ was prepared by transferring $100 \mathrm{mg}$ of SWCNT in $1 \mathrm{~L}$ of the ASTM medium in a Pyrex glass beaker and dispersing using probe sonication for $10 \mathrm{~min}$ at $80 \mathrm{~W}$ (Ultrasonic processor, frequency $25 \mathrm{kHz}$, Misonix S4000). 


\section{Culture of D. magna}

D. magna were cultured according to Environment Canada procedures, in reconstituted M4 medium: $\mathrm{NaHCO}_{3}\left(64.8 \mathrm{~g} \mathrm{~L}^{-1}\right) ; \mathrm{CaCl}_{2} 2 \mathrm{H}_{2} \mathrm{O}\left(293.8 \mathrm{~g} \mathrm{~L}^{-1}\right) ; \mathrm{MgSO}_{4} 7 \mathrm{H}_{2} \mathrm{O}\left(123.3 \mathrm{~g} \mathrm{~L}^{-1}\right)$ and $\mathrm{KCl}$ (5.8 $\mathrm{g} \mathrm{L}^{-1}$ ); $\mathrm{pH}$ 7-8; hardness 230-260 $\mathrm{mg} \mathrm{CaCO}_{3} \mathrm{~L}-1$ (Environment-Canada 1990). Organisms were placed into an experimental chamber with programmed temperature and photoperiods $\left(20^{\circ} \mathrm{C} \pm 2\right.$, 16/8 h Light/Dark). Animals were fed daily with algae Pseudokirchneriella subcapitata (30 mL; 1.8 $\mathrm{x} 106$ cells $\mathrm{mL}^{-1}$ ) and once a week with beef extract. The medium was renewed every week. All assays were conducted in a chamber under the same temperature and photoperiod regime using ASTM medium.

\section{Adsorption of Cd on SWCNT}

The interaction of Cd with SWCNT was measured by performing traditional adsorption batch experiment and measuring remaining $\mathrm{Cd}$ concentration in the aqueous phase by ICP-MS. Various volumes of SWCNT stock solution $\left(0.1 \mathrm{~g} \mathrm{~L}^{-1}\right)$ were mixed with various volumes of $\mathrm{Cd}$ stock solution $\left(\mathrm{CdCl} 2 ; 25\right.$ to $\left.450 \mu \mathrm{g} \mathrm{Cd} \mathrm{L}^{-1}\right)$ and water. Cd adsorption at a specific concentration of SWCNT $\left(1 \mathrm{mg} \mathrm{L}^{-1}\right)$ was investigated at various metal concentrations $(25,50,100,200$, and $450 \mu \mathrm{g}$ $\mathrm{Cd} \mathrm{L}^{-1}$ ). The $\mathrm{pH}$ of the suspensions was measured and found to be between 8 and 8.5. Cd-SWCNT suspensions were prepared in duplicate and shaken for $48 \mathrm{~h}$ to achieve the adsorption at $23 \pm 1{ }^{\circ} \mathrm{C}$. In addition, a control with cadmium alone $\left(415 \mu \mathrm{g} \mathrm{L}^{-1}\right)$ was used to examine the potential occurrence of $\mathrm{Cd}$ precipitation under the current conditions. Small sample aliquots were withdrawn at $24 \mathrm{~h}$ and $48 \mathrm{~h}$ for further analysis by ICP-MS. The amount of Cd on SWCNT was calculated by Eq. (2) (Moradi et al. 2011):

$$
\mathrm{qe}_{\mathrm{e}}=\left(\mathrm{C}_{0}-\mathrm{Ce}_{\mathrm{e}}\right) \mathrm{V} / \mathrm{w}
$$

Where $\mathrm{C} 0$ (mg L-1) is the initial Cd concentration, $\mathrm{Ce}(\mathrm{mg} \mathrm{L}-1)$ is the final $\mathrm{Cd}$ concentration at equilibrium (mg g-1), V (L) and w (g)

\section{Toxicity tests}

\section{Exposure to Cd or SWCNT}

Before and during the study, $\mathrm{K}_{2} \mathrm{Cr}_{2} \mathrm{O}_{7}$ (Sigma-Aldrich) was used as a reference toxicant (positive control) to evaluate the quality of cultured organisms (concentration range $0.175-2.8 \mathrm{mg}$ $\mathrm{L}^{-1}$ ). Other test validation criteria (e.g. response in the negative control, temperature) were verified against guidelines criteria and laboratory in-house control data.

Stock solutions of $\mathrm{Cd}\left(\mathrm{CdCl}_{2}, 1 \mathrm{~g} \mathrm{~L}^{-1}\right)$ and SWCNT $\left(0.1 \mathrm{~g} \mathrm{~L}^{-1}\right)$ were prepared directly in the ASTM culture medium. Organisms were exposed according to standardised tests (EnvironmentCanada 1990). Five test concentrations and one control group were used, each with four replicates. Each replicate consisted of five D. magna neonates $(<24 \mathrm{~h})$ in a $150 \mathrm{~mL}$ glass beaker containing $100 \mathrm{~mL}$ test solution. $\mathrm{CdCl}_{2}$ and SWCNT concentrations used were respectively between $25-525$ $\mu \mathrm{g} \mathrm{L}^{-1}$ (measured concentrations of $\mathrm{Cd}$ ) and $0.5-10 \mathrm{mg} \mathrm{L}^{-1}$ (nominal concentrations of SWCNT). The glass beakers were covered with a glass lid and beakers were incubated for $48 \mathrm{~h}$ at $20 \pm 2{ }^{\circ} \mathrm{C}$ and 16/8 h Light/Dark condition. After $48 \mathrm{~h}$ of exposure, immobile organisms were placed under a binocular microscope for heart beat observation and the percentage of surviving organisms was calculated for each condition. The residual suspensions of test solutions were used for the measurement of $\mathrm{Cd}$ concentration.

To test if the toxicity observed could be related to impurities released from SWCNT, $D$. magna were exposed to filtered solutions of SWCNT. The nominal test concentrations assayed were prepared by sonication of SWCNT in ASTM and then filtered using a $0.22 \mu \mathrm{m}$ filter (EMD, PES membrane) to remove carbon nanotubes. Reduction/ elimination of carbon nanotubes was verified by measuring their absorption at $800 \mathrm{~nm}$ using spectrophotometry and TEM analysis.

\section{Toxicity test of Cd and SWCNT combined}

The potential impact of SWCNT on Cd toxicity was investigated under the same conditions as the $\mathrm{Cd}$ toxicity evaluation described above. Briefly, two series of different concentrations of $\mathrm{Cd}$ 
( 25 to $525 \mu \mathrm{g} \mathrm{L}^{-1}$ ) were prepared as described previously. Then, each series received a non toxic concentration of SWCNT (500 or $1000 \mu \mathrm{g} \mathrm{L}^{-1}$ ). The suspensions were mixed prior to the addition of Daphnia neonates.

\section{Chemical analysis}

$\mathrm{Cd}$ concentrations were measured at the end of each lethality test and sorption experiment. Briefly, the solutions were transferred into polypropylene tubes with $5 \%$ nitric acid. Samples with SWCNT and/or Cd were filtered with a $0.22 \mu \mathrm{m}$ filter (EMD, PES) to remove carbon nanotubes. After dilution, residual $\mathrm{Cd}$ concentrations were measured using inductively coupled plasma mass spectrometry (ICP-MS, X series 2, Thermo scientific).

During analysis, blanks and two certified reference materials (ERA from water company Water Co. and SLRS-5: River water reference material for trace metals from National research Canada) were also analyzed to verify contamination and analytical accuracy. $95 \%$ recovery values were obtained.

\section{Statistical analysis}

The lethal concentration (LC50) was calculated using probit analysis or Trimmed SpearmanKaber with the TOXCAL program (1996, software package version 5).

Statistical differences between treatments were assessed by Shapiro-Wilk test; the Bartlett test and the Levene test to assess normality and homoscedasticity, respectively. Data that fulfilled the normality and homoscedasticity assumptions were analyzed through one-way ANOVA followed by Tukey's test. Remaining data were analyzed with the Kruskal-Wallis test followed by multiple comparisons like Steel Dwass. Analysis was performed with JMP IN 4 software.

\section{Results and discussion}

\section{Characterization of SWCNT}

Characterization of dry SWCNT by TGA analysis confirmed raw nature of the sample with $60 \%$ of unpurified SWCNT oxidized, $20 \%$ of highly pure and defect-free SWCNT and residual mass of $20 \%$ corresponding to the fully oxidized catalysts metals, as previously reported (Dillon et al. 2005, Kim et al. 2007). Raman spectrum analysis revealed the presence of aldehyde groups $(\mathrm{CHO})$ at the end of nanotubes and inclusions other than pure carbon in the sample like amorphous carbon (data not shown). The SWCNT diameter was estimated at $1.53 \mathrm{~nm}$ based on RBM method. The FEG-SEM and TEM analysis revealed the presence of impurities on nanotubes (Figure 1). In solution, SWCNT formed large agglomerates with an average hydrodynamic size (by DSL technique) ranging from 582.6 to $1614 \mathrm{~nm}$, and an electrophoretic mobility with a minimum value of $-1.6 \times 10^{-9} \mathrm{~m}^{2} \mathrm{~V}-1 \mathrm{~s}-1$ and a maximum of $-1.4 \times 10^{-9} \mathrm{~m}^{2} \mathrm{~V}-1 \mathrm{~s}-1$ (mean $=-1.1 \pm 0.1 \mathrm{SD}$ ).

\section{Adsorption characteristics of Cd on SWCNT}

Adsorption experiments were carried out by mixing known amounts of carbon nanotubes with $\mathrm{Cd}$ solutions at different concentrations after an equilibrium period of $48 \mathrm{~h}$. The interaction between SWCNT and Cd was evaluated by measuring the sorption equilibrium concentration (Figure 2) after $48 \mathrm{~h}$.

The Langmuir isotherm was used to fit the experimental data with Eq. (3) (Jaroniec 1983):

$$
q_{e}=\frac{K_{a} q_{m} C_{e}}{1+K_{a} C_{e}}
$$

Where Ce (mg L-1) is the equilibrium Cd concentration $\left(\mathrm{mg} \mathrm{kg}^{-1}\right)$, $\mathrm{qm}\left(\mathrm{mg} \mathrm{kg}^{-1}\right)$ is the maximum adsorption capacity which considers a complete monolayer coverage and $\mathrm{Ka}\left(\mathrm{L} \mathrm{mg}^{-1}\right)$ is the Langmuir constant indirectly related to the energy of adsorption.

The reasonable fit of the Langmuir isotherm model was confirmed by the correlation coefficient tested $\left(\mathrm{r}^{2}=0.88\right)$ which is close to 1 . The qm value calculated by the Langmuir equation is $24.4 \mathrm{mg} \mathrm{kg}-1$. Therefore, the toxic effect of a Cd-SWCNT combination should be similar to 
effect of Cd alone because in our condition, SWCNT does not seem to concentrate Cd from water. The Langmuir equation has been widely used in metal adsorption studies. This model assumes a monolayer coverage of adsorbate over a homogeneous adsorbent surface with an equal adsorption activation energy for each molecule adsorbed onto the surface.
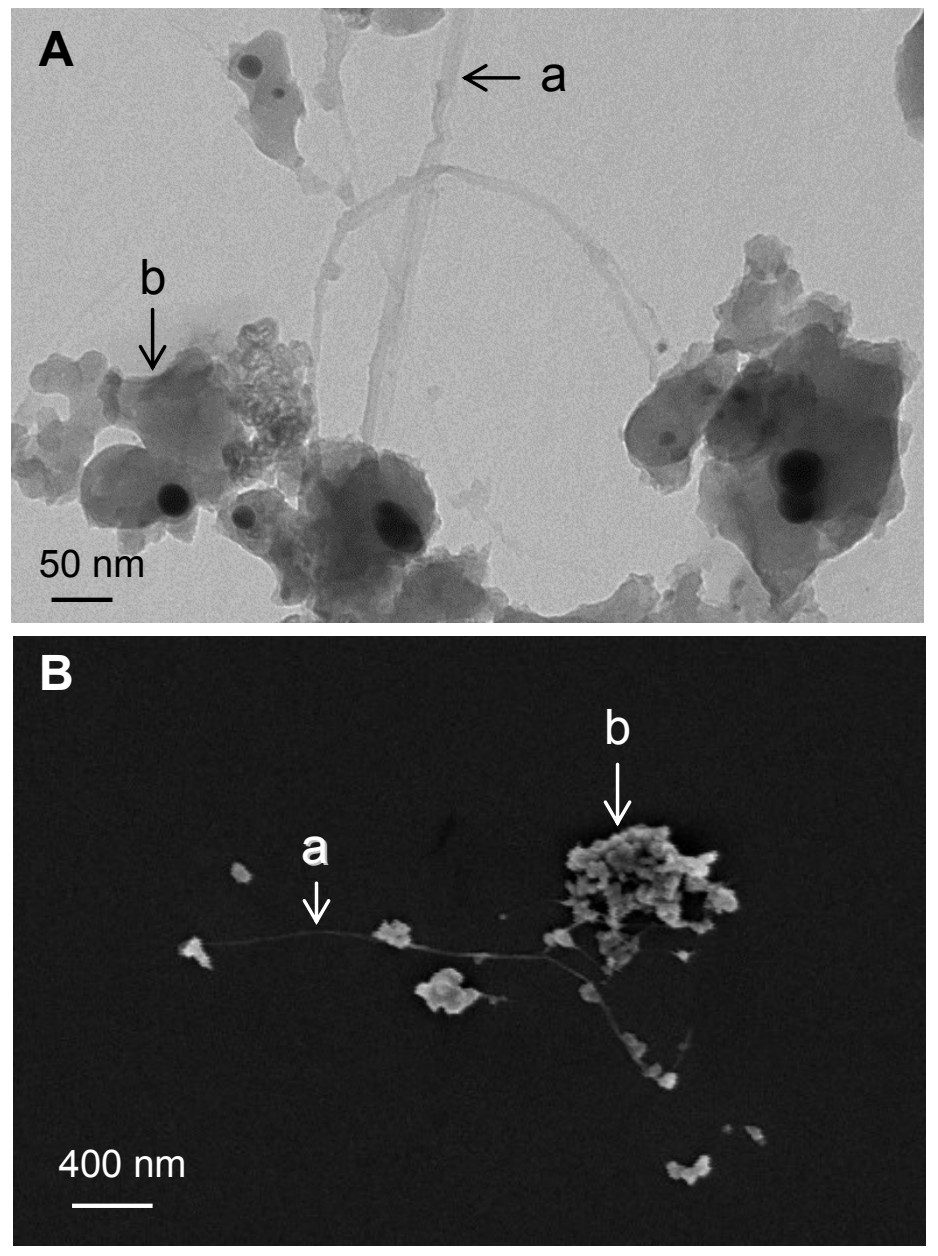

Figure 1. SWCNT observed with (A) field emission gun scanning electron microscopy and (B) transmission electron microscopy. Both techniques allow visualisation of (a) carbon nanotubes and (b) impurities forming rounded aggregates.

Previously, SWCNT were reported to have various adsorption capacities towards metals. For Cd, adsorption capacities of 18.58 and $52.35 \mathrm{mg} \mathrm{Cd} \mathrm{g-1} \mathrm{of} \mathrm{as-produced} \mathrm{or} \mathrm{carboxylate} \mathrm{group}$ functionalized SWCNT were calculated respectively (Moradi et al. 2011). It appears that the variability of $\mathrm{Cd}$ adsorption capacity on SWCNT is related to the different production and purification methods ( $\mathrm{Li}$ et al. 2004, Li et al. 2005). In particular, the presence of carboxylate groups on the surface of SWCNT enables a more effective metal adsorption. 


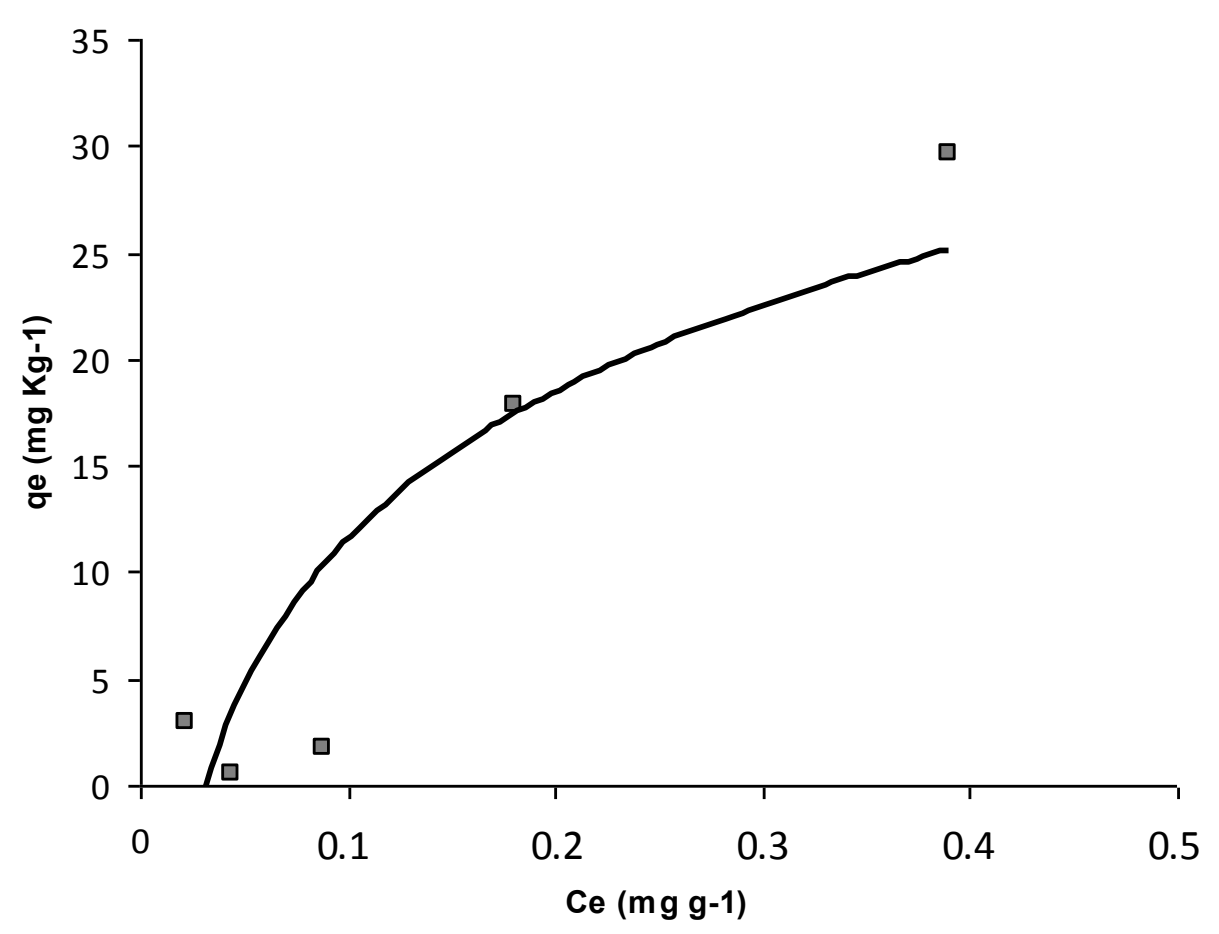

Figure 2. Adsorption isotherm for Cd ions at a concentration of $1 \mathrm{mg} / \mathrm{L} \mathrm{SWCNT}$.

\section{Toxicity of Cd or SWCNT}

The water quality parameters for the toxicity tests were all within the acceptable ranges: $19.5-21^{\circ} \mathrm{C}$ for temperature, $95-100 \%$ for dissolved oxygen, $8.0-8.1 \mathrm{for} \mathrm{pH}$ and $643-750 \mu \mathrm{S} / \mathrm{cm}$ for conductivity. Ammonia and nitrite concentration remained very low and water hardness was measured to be between 240 and $290 \mathrm{mg} \mathrm{L}-1$. All toxicity tests performed were valid according to the criteria mentioned in the respective guidelines, i.e. for reproducible tests mortality is inferior to $10 \%$.

Figure 3 presents the results of three tests where $D$. magna neonates were exposed to $\mathrm{Cd}$ alone. Reproducible dose-response curves were obtained and the LC50 determined was $252.3 \mu \mathrm{g} \mathrm{L}^{-}$ 1. Previous studies have reported the toxicity of Cd to D. magna under different medium and culturing conditions than those mentioned in the current publication (Bodar et al. 1988, Ferreira et al. 2008, Qu et al. 2013). These studies showed a decrease in survival of D. magna at concentrations up to $300 \mu \mathrm{g} \mathrm{L}^{-1}$ in good agreement with the values measured herein.

Figure 3 presents the survival of $D$. magna neonates after exposure to SWCNT alone. The LC50 determined was $1400 \mu \mathrm{g} \mathrm{L}^{-1}$. In recent years, the development of new applications for carbon nanotubes has been increasing. Several studies have investigated the toxicity of SWCNT towards aquatic invertebrates. Earlier work has shown that a $48 \mathrm{~h}$ exposure of carbon nanotubes at $400 \mu \mathrm{g} \mathrm{L}$ 1 could induce lethality in D. magna (Petersen et al. 2009). Several authors have investigated the food particle size of D. magna, which appears to be between 100 and $5000 \mathrm{~nm}$ (Geller and Müller 1981).

Because it is in the range of agglomerates size of SWCNT measured in our study, carbon nanotubes are likely to accumulate in the digestive tract of organisms and decrease food intake (Petersen et al. 2009, Petersen et al. 2011). This hypothesis has been confirmed by our observations of survivors that showed the presence of SWCNT in the digestive tract of daphnids exposed to 500 and $1000 \mu \mathrm{g} \mathrm{L}-1$, while SWCNT were also observed on the body surface of daphnids exposed to $1000 \mu \mathrm{g} \mathrm{L-1}$ (Figure 4). A feeding rate test could complement this hypothesis. Earlier work has shown the presence of carbon nanotubes in the gastrointestinal track of D. magna using light, binocular and transmission electron microscopy (Baun et al. 2008, Petersen et al. 2009, Mwangi et al. 2012). 

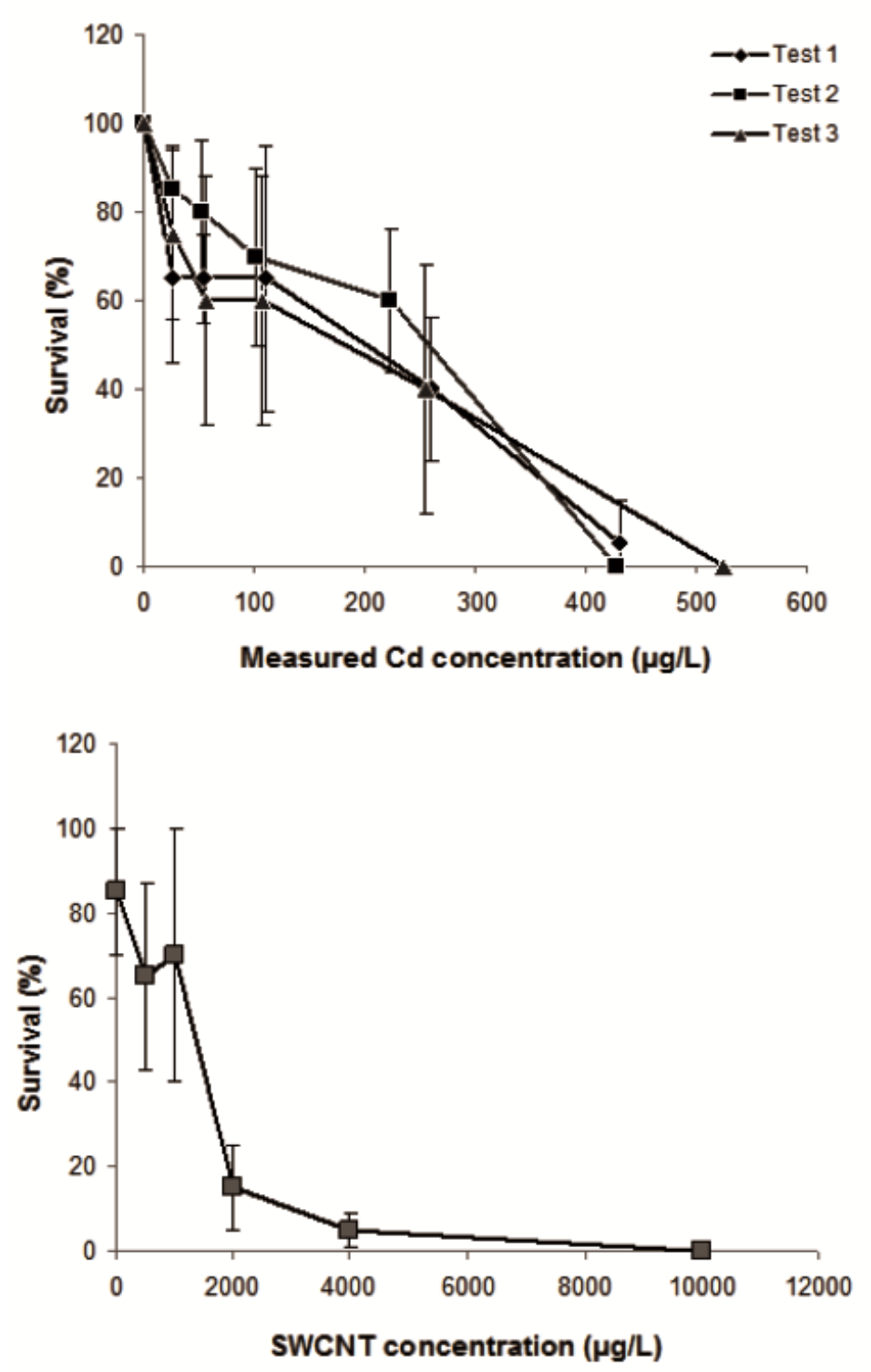

Figure 3. Toxicity of Cd and SWCNT to D. magna after $48 \mathrm{~h}$ of exposure.

Previously, metal impurities in carbon nanotubes were reported to disturb the hatching delay of zebrafish (Cheng et al. 2007). A 48-h lethality test was thus carried out to study the effect of a pre-sonicated filtered SWCNT solution. No significant differences between the control and other treatments were measured with a mean of survival $>85 \%$ (data not shown), and observation of organisms did not reveal any accumulation of SWCNT in the digestive tract. Therefore, we concluded that the filtered SWCNT solutions were not toxic in our model, even though the sonication process for the dispersion of SWCNT was operated for a period long enough to dissolve impurities in the medium (Toh et al. 2012). In this study, the toxicity of SWCNT to D. magna was thus attributed to the accumulation of SWCNT in the digestive tract rather than to the dissolution of impurities.

\section{Toxicity of Cd in the presence of SWCNT}

In natural environments, organisms are exposed to multiple contaminants. Furthermore, nanomaterials are highly reactive for their large surface area, for instance. To evaluate the toxicity of carbon nanomaterials it is crucial to consider possible interactions with other toxic substances such as metals or organic contaminants. Indeed, the surface properties and adsorption capacity of 
carbon nanotubes facilitate binding of compounds present in the environment or in test medium such as contaminants and influence their toxicity (Bhatt and Tripathi 2011, Al-Shaeri et al. 2013).

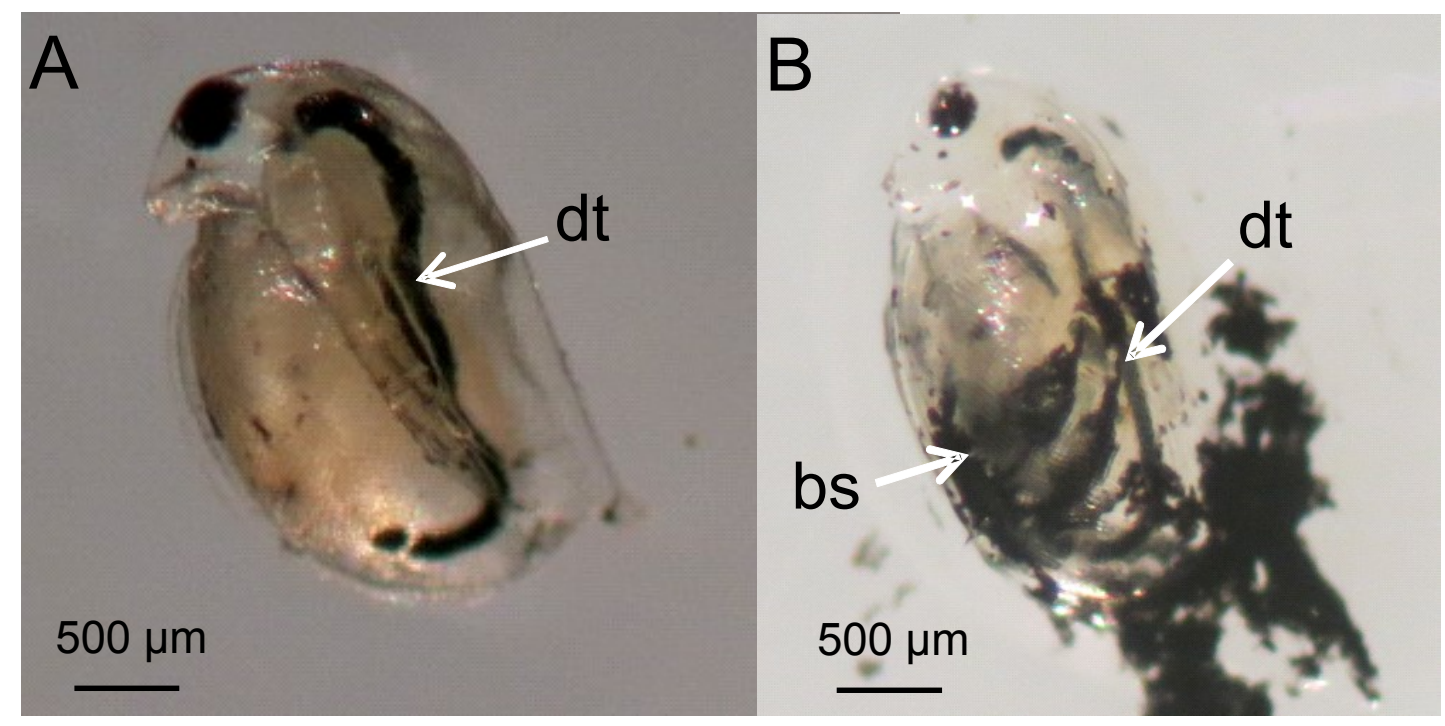

Figure 4. Binocular images of D. magna exposed to SWCNT after $48 \mathrm{~h}$ exposure to a suspension of (A) $500 \mu \mathrm{g} \mathrm{L}^{-1}$ and (B) $1000 \mu \mathrm{g} \mathrm{L}^{-1}$. The black colour in the digestive tract (dt) or on the body surface (bs) shows the uptake and interaction with SWCNT.

The presence of SWCNT at 500 and $1000 \mu \mathrm{g} / \mathrm{L}$ enhanced the toxicity of Cd by a factor 2 with a LC50 of 127.2 and $120.1 \mu \mathrm{g} \mathrm{L}^{-1}$, respectively (Figure 5). A stronger effect was measured for SWCNT at $1000 \mu \mathrm{g} / \mathrm{L}$ with lower variability. To our knowledge this is the first study to report a decrease in D. magna survival by a co-exposition to SWCNT and Cd. A previous study showed an increase of $\mathrm{Cd}$ accumulation in the liver of the goldfish (Carassius auratus) after $12 \mathrm{~d}$ exposure in the presence of oxidized multi-walled carbon nanotubes (Qu et al. 2014). Martinez et al. (2013) reported the increase of lead toxicity to the Nile tilapia (Oreochromis niloticus) in the presence of purified MWCNT (Martinez et al. 2013). Another study measured a potentiating effect of SWCNT exposed with $\mathrm{Cd}$ or $\mathrm{Zn}$ on the DNA damage measured in the hemocytes of the blue mussel (Mytilus edulis) (Al-Shaeri et al. 2013).

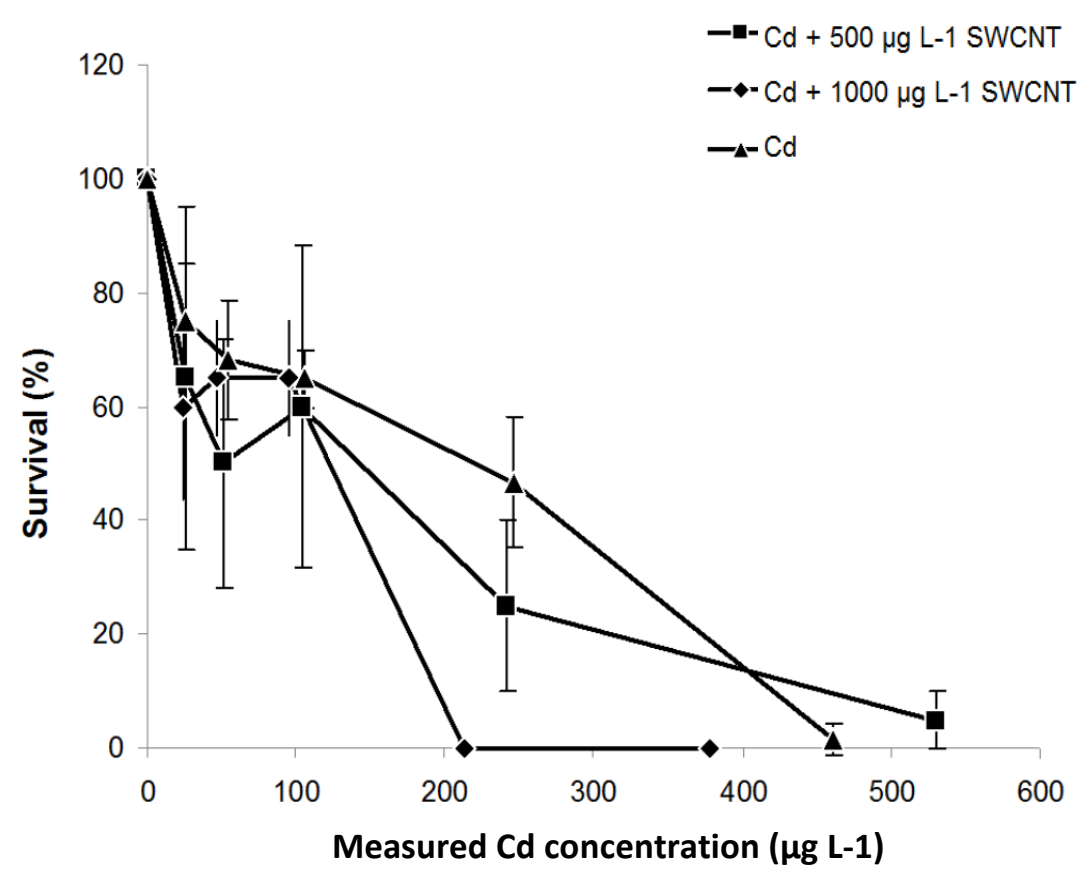

Figure 5. Toxicity of Cd with or without SWCNT after $48 \mathrm{~h}$ of exposure. 
Although in our study SWCNT have a low adsorption capacity for Cd, the results suggest that they can still interact with $\mathrm{Cd}$ species and influence the toxicity to the organisms exposed. To our knowledge this is the first study highlighting such an effect in the presence of SWCNT with a low adsorption capacity. The accumulation of carbon nanotubes on the outer surface of daphnia and inside the digestive tract, as observe in binocular images (Figure 4), may induce a higher intake of $\mathrm{Cd}$. The physicochemical conditions of the digestive tract of D. magna found in the literature (Hasler 1935, Weltens et al. 2000) support the hypothesis that Cd would then be desorbed and released into the intestine. Indeed, even though the $\mathrm{pH}$ is neutral in the Daphnia gastro-intestinal tract (Pennak 1978), enzymatic conditions can favor desorption processes (Lampert 1987, Weltens et al. 2000). To confirm the implicated mechanism implicated in toxicity, measurement of SWCNT and $\mathrm{Cd}$ intake by D. magna should be further investigated with quantification of contaminants into the organisms.

\section{Conclusion}

SWCNT possess a large surface area that enhances their ability to adsorb contaminants. This property is appealing for wastewater treatment (Tan et al. 2012), but also threatening for organisms that could interact with contaminants adsorbed on the surface of carbon nanotubes. Our goal in this study was to evaluate the effect of the presence of SWCNT on the toxicity of Cd to the crustacean D. magna. The results showed that SWCNT had a low adsorption capacity for Cd but increased the toxicity of the metal to D. magna. We assume that the observed effects are caused by the uptake of free cadmium species and Cd adsorbed on SWCNT by the organisms. Our study shows how the understanding of SWCNT interactions with other contaminants is important to evaluate the consequences of their release in the environment.

\section{Acknowledgements}

We would like to thank Dr. Benoit Simard and Amy Hirdina from the National Research Council Canada (NRCC - Ottawa, ON) for the production and characterization of dry raw SWCNT, Florence Perrin (NRCC - Boucherville, QC) for scanning electron microscopy images and Micheline Letarte (INRS-Institut Armand-Frappier, QC) for transmission electron microscopy. We sincerely thank Patrice Turcotte (from Environment Canada) for cadmium analysis, Fanny MonteilRivera for her comments and Christine Kleinert for proofreading the manuscript. We thank the INRS Armand Frappier Foundation for the PhD scholarship awarded to Messika Revel.

\section{References}

[1] Al-Shaeri, M., D. Ahmed, F. McCluskey, G. Turner, L. Paterson, E. A. Dyrynda and M. G. J. Hartl (2013). Potentiating toxicological interaction of single-walled carbon nanotubes with dissolved metals. Environ Toxicol Chem 32(12): 2701-2710.

[2] Alloy, M. M. and A. P. Roberts (2011). Effects of suspended multi-walled carbon nanotubes on daphnid growth and reproduction. Ecotoxicol Environ Saf 74(7): 1839-1843.

[3] ASTM (2014). E729-96. Standard Guide for Conducting Acute Toxicity Tests on Test materials with fishes, macroinvertebrates, and amphibians, ASTM International, West Conshohocken, PA, 2014.

[4] Attar, E. N. and E. J. Maly (1982). Acute toxicity of cadmium, zinc, and cadmium-zinc mixtures to Daphnia magna. Arch Environ Contam Toxicol 11(3): 291-296.

[5] Baun, A., S. N. Sørensen, R. F. Rasmussen, N. B. Hartmann and C. B. Koch (2008). Toxicity and bioaccumulation of xenobiotic organic compounds in the presence of aqueous suspensions of aggregates of nano-C60. Aquat Toxicol 86(3): 379-387. 
[6] Bhatt, I. and B. N. Tripathi (2011). Interaction of engineered nanoparticles with various components of the environment and possible strategies for their risk assessment. Chemosphere 82(3): 308-317.

[7] Biesinger, K., L. Williams and W. Schalie. (2002). Procedures for conducting 'Daphnia magna' toxicity bioassays. . USER'S GUIDE. U.S. Environmental Protection Agency, Washington, D.C., EPA/600/8-87/011 (NTIS PB88124722).

[8] Bodar, C. W. M., C. J. Van Leeuwen, P. A. Voogt and D. I. Zandee (1988). Effect of cadmium on the reproduction strategy of Daphnia magna. Aquat Toxicol 12(4): 301-309.

[9] Cheng, J., E. Flahaut and S. H. Cheng (2007). Effect of carbon nanotubes on developing zebrafish (Danio Rerio) embryos. Environ Toxicol Chem 26(4): 708-716.

[10] Dillon, A. C., P. A. Parilla, J. L. Alleman, T. Gennett, K. M. Jones and M. J. Heben (2005). Systematic inclusion of defects in pure carbon single-wall nanotubes and their effect on the Raman D-band. Chem. Phys. Lett. 401(4-6): 522-528.

[11] Dresselhaus, M. S., G. Dresselhaus and A. Jorio (2004). Unusual properties and structure of carbon nanotubes. Annu Rev Mater Res 34: 247-278.

[12] Environment-Canada (1990). Biological Test Method: Acute Lethality Test Using Daphnia spp. Report EPS 1/RM/11. Environment Canada, Ottawa, Ontario, Canada: 55.

[13] Ferguson, P. L., G. T. Chandler, R. C. Templeton, A. Demarco, W. A. Scrivens and B. A. Englehart (2008). Influence of sediment - Amendment with single-walled carbon nanotubes and diesel soot on bioaccumulation of hydrophobic organic contaminants by benthic invertebrates. Environ Sci Technol 42(10): 3879-3885.

[14] Ferreira, A. L. G., S. Loureiro and A. M. V. M. Soares (2008). Toxicity prediction of binary combinations of cadmium, carbendazim and low dissolved oxygen on Daphnia magna. Aquat Toxicol 89(1): 28-39.

[15] Geller, W. and H. Müller (1981). The filtration apparatus of Cladocera: Filter mesh-sizes and their implications on food selectivity. Oecologia 49(3): 316-321.

[16] Giusto, A., L. A. Somma and L. Ferrari (2012). Cadmium toxicity assessment in juveniles of the Austral South America amphipod Hyalella curvispina. Ecotoxicol Environ Safety 79(0): 163169.

[17] Hare, L. (1992). Aquatic Insects and Trace Metals: Bioavailability, Bioaccumulation, and Toxicity. Crit Rev Toxicol 22(5-6): 327-369.

[18] Hasler, A. D. (1935). The physiology of digestion of plankton crustacea: I. Some digestive enzymes of daphnia. Biol Bull 68(2): 207-214.

[19] Jaroniec, M. (1983). Physical adsorption on heterogeneous solids. Adv. Colloid Interface Sci. 18(3-4): 149-225.

[20] Kennedy, A. J., M. S. Hull, J. A. Steevens, K. M. Dontsova, M. A. Chappell, J. C. Gunter and C. A. Weiss $\operatorname{Jr}$ (2008). Factors influencing the partitioning and toxicity of nanotubes in the aquatic environment. Environ Toxicol Chem 27(9): 1932-1941.

[21] Kim, K. S., G. Cota-Sanchez, C. T. Kingston, M. Imris, B. Simard and G. Soucy (2007). Large-scale production of single-walled carbon nanotubes by induction thermal plasma. J. Phys. D: Appl. Phys 40(8): 2375-2387.

[22] Kim, K. S., G. Cota-Sanchez, C. T. Kingston, M. Imris, B. Simard and G. Soucy (2007). Large-scale production of single-walled carbon nanotubes by induction thermal plasma. J. Phys. D: Appl. Phys. 40(8): 2375-2387.

[23] Lampert, W. (1987). Feeding and nutrition in Daphnia. Mem. Ist. Ital. Idrobiol 45: 143-192. 
[24] Lazorchak, J. M., M. E. Smith and H. J. Haring (2009). Development and validation of a Daphnia magna four-day survival and growth test method. Environ Toxicol Chem 28(5): 10281034.

[25] Li, M. and C. P. Huang (2011). The responses of Ceriodaphnia dubia toward multi-walled carbon nanotubes: Effect of physical-chemical treatment. Carbon 49(5): 1672-1679.

[26] Li, Y.-h., Z.-c. Di, Z.-k. Luan, J. Ding, H. Zuo, X.-q. Wu, C.-L. Xu and D.-h. Wu (2004). Removal of heavy metals from aqueous solution by carbon nanotubes: adsorption equilibrium and kinetics. J. Environ. Sci 16(2): 208-211.

[27] Li, Y.-H., Z. Di, J. Ding, D. Wu, Z. Luan and Y. Zhu (2005). Adsorption thermodynamic, kinetic and desorption studies of Pb2+ on carbon nanotubes. Water Res 39(4): 605-609.

[28] Lu, C., H. Chiu and C. Liu (2006). Removal of Zinc(Iijima) from Aqueous Solution by Purified Carbon Nanotubes: Kinetics and Equilibrium Studies. Ind Eng Chem Res 45(8): 28502855.

[29] Martinez, D. S. T., O. L. Alves and E. Barbieri (2013). Carbon nanotubes enhanced the lead toxicity on the freshwater fish. J. Phys Conference Series 429(1).

[30] Moore, M. N. (2006). Do nanoparticles present ecotoxicological risks for the health of the aquatic environment? Environ Int 32(8): 967-976.

[31] Moradi, O., K. Zare and M. Yari (2011). Interaction of some heavy metal ions with single walled carbon nanotube. Int J Nano Dimens 1(3): 203-220.

[32] Mwangi, J. N., N. Wang, C. G. Ingersoll, D. K. Hardesty, E. L. Brunson, H. Li and B. Deng (2012). Toxicity of carbon nanotubes to freshwater aquatic invertebrates. Environ Toxicol Chem 31(8): 1823-1830.

[33] OECD Test No. 211: Daphnia magna Reproduction Test, OECD Publishing.

[34] Pennak (1978). Cladocera (water fleas). In Freshwater invertebrates of the United States. John Wiley \& Sons, New York.

[35] Petersen, E. J., J. Akkanen, J. V. K. Kukkonen and W. J. Weber (2009). Biological Uptake and Depuration of Carbon Nanotubes by Daphnia magna. Environ Sci Technol 43(8): 2969-2975.

[36] Petersen, E. J., J. Akkanen, J. V. K. Kukkonen and W. J. Weber (2009). Biological Uptake and Depuration of Carbon Nanotubes by Daphnia magna. Environmental Science \& Technology 43(8): 2969-2975.

[37] Petersen, E. J., R. A. Pinto, D. J. Mai, P. F. Landrum and W. J. Weber Jr (2011). Influence of polyethyleneimine graftings of multi-walled carbon nanotubes on their accumulation and elimination by and toxicity to Daphnia magna. Environ Sci Technol 45(3): 1133-1138.

[38] Qu, R., X. Wang, Z. Wang, Z. Wei and L. Wang (2014). Metal accumulation and antioxidant defenses in the freshwater fish Carassius auratus in response to single and combined exposure to cadmium and hydroxylated multi-walled carbon nanotubes. J Hazard Mater 275: 89-98.

[39] Qu, R. J., X. H. Wang, M. B. Feng, Y. Li, H. X. Liu, L. S. Wang and Z. Y. Wang (2013). The toxicity of cadmium to three aquatic organisms (Photobacterium phosphoreum, Daphnia magna and Carassius auratus) under different pH levels. Ecotoxicol Environ Safety 95(0): 83-90.

[40] Souid, G., N. Souayed, F. Yaktiti and K. Maaroufi (2013). Effect of acute cadmium exposure on metal accumulation and oxidative stress biomarkers of Sparus aurata. Ecotoxicol Environ Safety 89(0): 1-7.

[41] Tan, C., K. Tan, Y. Ong, A. Mohamed, S. Zein and S. Tan (2012). Energy and environmental applications of carbon nanotubes. Environ Chem Lett 10(3): 265-273. 
[42] Templeton, R. C., P. L. Ferguson, K. M. Washburn, W. A. Scrivens and G. T. Chandler (2006). Life-cycle effects of single-walled carbon nanotubes (SWNTs) on an estuarine meiobenthic copepod. Environ Sci Technol 40(23): 7387-7393.

[43] Toh, R. J., A. Ambrosi and M. Pumera (2012). Bioavailability of metallic impurities in carbon nanotubes is greatly enhanced by ultrasonication. Chem Eur J 18(37): 11593-11596.

[44] USGS. Mineral Commodity Summaries. U.S. Geological Survey: 36-37. 2013

[45] Vellinger, C., M. Parant, P. Rousselle, F. Immel, P. Wagner and P. Usseglio-Polatera (2012). Comparison of arsenate and cadmium toxicity in a freshwater amphipod (Gammarus pulex). Environ Poll 160(0): 66-73.

[46] Wang, W. X. and P. S. Rainbow (2006). Subcellular partitioning and the prediction of cadmium toxicity to aquatic organisms. Environ Chem 3(6): 395-399.

[47] Weltens, R., R. Goossens and S. Van Puymbroeck (2000). Ecotoxicity of Contaminated Suspended Solids for Filter Feeders (Daphnia magna). Arch Environ Contam Toxicol 39(3): 315 323.

[48] Weltens, R., R. Goossens and S. Van Puymbroeck (2000). Ecotoxicity of Contaminated Suspended Solids for Filter Feeders (Daphnia magna). Arch Environ Contam Toxicol 39(3): 315323.

[49] Wen-Hong, F., G. Tang, C. M. Zhao, Y. Duan and R. Zhang (2009). Metal accumulation and biomarker responses in Daphnia magna following cadmium and zinc exposure. Environ Toxicol Chem 28(2): 305-310.

[50] Wijnhoven, S., Ir. A.G. Oomen, A.J.A.M. Sips, F.C. Bourgeois, G.J.P.M. te Dorsthorst, M.W. Kooi and M. I. Bakker (2011). Development of an inventory for consumer products containing nanomaterials Final Report. ENV/D3/SER/2010/0060r European commission.

[51] Youn, S., R. Wang, J. Gao, A. Hovespyan, K. J. Ziegler, J. C. J. Bonzongo and G. Bitton (2012). Mitigation of the impact of single-walled carbon nanotubes on a freshwater green algae: Pseudokirchneriella subcapitata. Nanotoxicology 6(2): 161-172. 